\title{
Artículos
}

\section{La revista electrónica y su aceptación en la comunidad científica}

\author{
Por Mari-Carmen Marcos
}

\begin{abstract}
Resumen: En los últimos años el incremento de revistas publicadas en formato electrónico ha llevado a las bibliotecas a plantearse la conveniencia de suscribirse a ellas como complemento al formato papel o, incluso, abandonando éste. El presente artículo define la revista electrónica científica, enumera los formatos en los que se presenta, las políticas seguidas por los editores, las ventajas e inconvenientes con respecto al formato tradicional, los sistemas de acceso provistos por editores y distribuidores y las peculiaridades que se plantean en la gestión bibliotecaria al incorporarlas a su fondo documental.
\end{abstract}

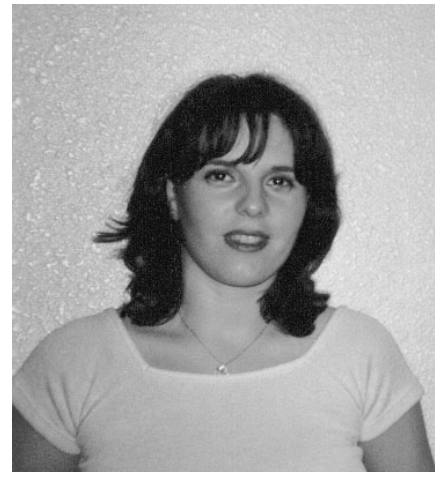

Mari-Carmen Marcos

Palabras clave: Revistas electrónicas, Revistas científicas, Acceso a revistas electrónicas, Gestión bibliotecaria.

\section{Title: Electronic journals and their acceptance by the scientific community}

Abstract: In the last few years the electronic journal increase has led librarians to think the fitness of subscribing them as an extension of print format or even abandoning this. In the present article the scientific e-journal is defined and the different formats are enumerated. We talk also about edition's politics, advantages and disadvantages with regard to traditional format, access systems provided by editors and distributors, and special features in library management.

Keywords: Electronic journals, Scientific journals, Electronic journals access, Library management

Marcos, Mari-Carmen. "La revista electrónica y su aceptación en la comunidad científica". En: El profesional de la información, 2000, mayo, v. 9, n. 5, pp. 4-14.

Desde el principio de su existencia, las revistas científicas han sido consideradas el medio de transmisión de conocimiento científico más importante, especialmente en el ámbito de las ciencias. En el campo de las ciencias sociales, y más acusadamente en el de las humanidades, todavía juega un gran papel el libro, si bien se tiende a un mayor uso de las revistas. Desde sus orígenes, en el siglo XIX, y hasta muy recientemente no se había alterado jamás su estructura ni su medio de distribución. Con los avances de la tecnología surge una nueva forma: la revista electrónica. Este medio ha supuesto una revolución en el ámbito científico; en palabras de Valauskas (1998) ha sido "el mayor avance en el discurso intelectual desde la invención de la imprenta", idea compartida por diversos autores a quienes él cita, si bien su implantación no es todavía una realidad tan habitual como podría esperarse.

El nacimiento de las revistas electrónicas ha seguido unos pasos muy claros. En las bases de datos referenciales se puede ver el primer intento de acercar al usuario de forma electrónica a la información contenida en las revistas. En ellas se ofrecían - y hoy todavía mantienen una gran importancia como fuentes de información- los datos de identificación de los artículos que poco más tarde se fueron completando con descriptores y resúmenes y actualmente con el texto completo y otros tipos de información como imágenes y sonidos. Sin duda la invención del disco compacto para datos - el cd-rom - supuso un gran avance al permitir el almacenamiento de grandes cantidades de datos, pero quizá el mayor impulso se dio con la llegada de internet, ya que hizo posible un acceso en línea más ventajoso que con las redes públicas anteriores (basadas en X.25) y facilitó la edición y distribución de información.

\section{Qué entendemos por revista científica electrónica}

El concepto de "información electrónica" puede resultar algo confuso, de hecho algunos autores como Barrueco y García Testal (1997) lo aplican exclusivamente a aquella que se transmite mediante redes de telecomunicaciones, mientras que otros como Edwards (1997) distinguen dentro del concepto "electrónica" la que se accede mediante una conexión en línea de las que se presentan en formatos como el cd-rom.

Es importante considerar esta diferencia a la hora de definir la revista electrónica — en adelante revistae-. Barrueco y García Testal (1997) ofrecen esta definición de revista-e científica: "conjunto de artículos ordenados, formalizados y publicados a través de redes teleinformáticas bajo la responsabilidad de una institución científica o técnica que entre otras cosas valide la calidad de la información publicada en la

Original recibido el 5-1-00

Aceptación definitiva: $28-2-00$ 


\section{¿Cuántas revistas-e científicas existen?}

No es posible conocer con exactitud su cifra. Por un lado los directorios disponibles no son exhaustivos ni se limitan en exclusiva a las publicaciones del ámbito científico, sino que incluyen boletines de asociaciones, listas de discusión, revistas divulgativas, magazines, etc. Por otro, la cantidad de publicaciones-e aumenta a mayor velocidad que las actualizaciones de estos directorios. Uno de ellos, muy útil, es Hyperjournal:

\section{http://www.ukoln.ac.uk/isg/hyperjournal/\#}

Para ofrecer unas cifras orientativas se puede citar el que goza por el momento de mayor prestigio, el $A R L$ Directory of electronic journals, newsletters and academic discussion lists de la Association of Research Libraries.

\section{http://www.arl.org/scomm/edir/index.html}

La $7^{\text {a }}$ edición de esta fuente, publicada en 1997 (y en abril de 2000 todavía la más reciente), recoge enlaces a 7.000 publicaciones de las cuales 3.400 son periódicas (el doble que en 1996) y de esas considera que 1.500 son revistas-e. Un $29 \%$ se encuentran dentro de la temática de la ciencia, un $28 \%$ tratan de ciencias sociales y un $14 \%$ acerca de artes y humanidades. Si se comparan las cifras de 1997 con las que aparecían en 1996 se observa que se pasó de 47 revistas con sistema de revisión de artículos a 1.000, y de 170 de pago a 700 .

Hay que tener en cuenta la subjetividad a la hora de considerar algunas revistas dentro del grupo de las científicas y tomar estos datos sólo como aproximados. La fuente NewJour, por comparar algunas cifras, contabilizaba en diciembre de 1995 625 títulos, 1.272 en septiembre de 1996 y 6.365 en septiembre de 1998 (Peek; Pomerantz, 1998).

misma". Si se entiende el concepto tal y como apuntan estos autores, existen tres condiciones para que se dé tal tipo de documento:

1. Los artículos deben estar agrupados de una forma ordenada y normalizada siguiendo un criterio.

2. La revista debe distribuirse a través de una red de telecomunicaciones —en este trabajo consideraremos igualmente electrónicas aquellas que se presenten en cd-rom-.

3. Debe existir una institución de tipo científico o técnico responsable de la edición y encargada de asegurar la calidad de los artículos publicados, al igual que ocurre en las publicaciones de este tipo en papel.

Respecto a la forma de distribución por medio de redes telemáticas, la evolución general de esta tecnología ha influido en la manera de hacer llegar las revistas a los lectores: en un primer momento se utilizaba el correo electrónico, después la transferencia de ficheros (ftp), más tarde la conexión remota (telnet) y, desde 1994 hasta hoy, la mayoría está disponible en la web.

\section{Pero ¿por qué surgen?}

La revista-e trata de solventar los problemas acusados en las publicadas en papel: el alto coste de producción y la lentitud del proceso de edición por un lado, y el aumento de títulos surgidos en la última década debido a la tendencia a la especialización en las materias de estudio.

Sus orígenes se remontan a la década de los 60, cuando se comenzó a usar la cinta magnética como formato para su almacenamiento y distribución. El invento no tuvo apenas éxito: ni se disponía de máquinas apropiadas, ni la comunidad académica estaba preparada para el cambio. Una década después, en los años 70, los estudios son mucho más viables, la National Science Foundation pretende crear un centro editorial donde preparar las revistas mediante un sistema electrónico, y el New Jersey Institute of Technology plantea el Electronic information exchange system (Eies). Peek y Pomerantz (1998) tratan los primeros años de las revistas-e.

El precio de las revistas ha aumentado de una forma sorprendente en los últimos años, y esto ha conducido a que las bibliotecas (sus clientes más numerosos) dejen muchas de las suscripciones por no poder afrontar este gasto. La solución adoptada por las editoriales ante esta disminución ha sido, de nuevo, el aumento de los precios para rentabilizar la pérdida de clientes. Las bibliotecas, por su parte, han decidido recurrir a servicios intermediarios que les proporcionen los artículos según los van necesitando, pagando sólo por ellos y no la suscripción a la revista completa.

Otra causa de la subida de precios es la que apuntan García Testal y Barrueco (1997): los autores prefieren publicar en revistas de alto prestigio para dar mayor difusión a sus trabajos, lo que lleva a las bibliotecas a tener que suscribirse a ellas. Los editores, que ven asegurados a sus clientes, suben el precio con la seguridad de que los usuarios van a seguir solicitando su producto.

\section{EI GER}

El Grupo Español de Revistas (GER) se reunió en Granada en octubre de 1997 para tratar el tema de las revistas-e. En este acontecimiento participaron distribuidores, editores y profesionales de bibliotecas universitarias y de investigación. Hoy, después de más de dos años, siguen en pie las preguntas que en esa cita quedaron sin respuesta: ¿se impondrá el formato electrónico sobre el papel para las revistas?, ¿cuál va a ser el rol de editores, distribuidores y bibliotecarios?, ¿variarán los costes? 


\section{Localización de revistas-e en la Red}

Redero (1998) opina que "la irrelevancia de la información que proporcionan los buscadores convencionales las hace difícilmente localizables cuando éstas no son ofrecidas por un distribuidor que cobra por sus servicios". El autor presenta en su artículo una relación de los principales buscadores de revistas científicas electrónicas de acceso gratuito en internet, disponible también en la siguiente URL:

http://web.usal.es/ redero/rev-e.htm

Ante esta situación del pez que se muerde la cola que está perjudicando tanto a editores (perdiendo clientes continuamente) como a bibliotecas y otros suscriptores (que se ven obligados a cancelar algunas revistas de interés para sus usuarios) surgen las revistas-e que, entre muchas de sus ventajas, abaratan los costes de producción y de distribución, si bien es cierto que existen otras características que hacen que ellos aumenten para las editoriales, como los que resultan del desarrollo informático, del soporte al cliente y la pérdida de ingresos por los medios tradicionales de publicidad.

\section{Una variedad de posibles formatos}

No se ha logrado dar todavía con el más idóneo para las revistas-e sino que cada editor elige aquel que más le conviene en función de sus necesidades. Así, el ascii apenas se utiliza actualmente si bien fue el que se tuvo que emplear en los primeros años. Como se ha dicho, en los comienzos, las revistas se distribuían vía correo electrónico pero pronto vieron en la web un medio mucho más cómodo. Hoy en día podemos recibir los sumarios a través del e-mail. Otro formato que también se ha usado, y todavía se emplea es el de imagen, es decir, se presenta la revista impresa digitalizada en un fichero de mapa de bits - tiff (tagged image file format) - , acompañado de los correspondientes ficheros ascii de cada página. Así lo hizo el proyecto $T u$ lip de Elsevier y lo ha continuado su sucesor EES (Elsevier electronic subscription) desde 1995. En la actualidad este servicio se denomina Sdos (ScienceServer onsite). Además de este servicio, Elsevier ofrece acceso a 1.100 revistas de 16 campos de la ciencia a través de Sciencedirect.

\section{http://www.scienceserver.com}

\section{http://www.sciencedirect.com}

Sin duda existen formatos más avanzados que éstos, pero no cuentan con la ventaja de poder representar símbolos matemáticos y químicos, como es el caso del html, que todavía no es capaz de hacerlo. A pesar de sus carencias, éste es, hoy en día, el más utilizado junto con pdf (portable document format) para la distribución de revistas-e. Cuenta con la ventaja de ser hipertextual y, gracias a ello, permite enlazar varias partes de un mismo artículo entre sí o con otros documentos. Además, las versiones actuales de los navegadores web pueden leer formatos gráficos y sonoros directamente o con la utilización de un plug-in. Pero en el caso de necesitar editar fórmulas, el html es insuficiente y hay que recurrir a otros formatos como latex (escrito originalmente LaTeX, no son siglas).

\section{«La edición electrónica plantea una solución a los altos costes de suscripción y la lentitud en el proceso de publicación de tra- bajos científicos»}

Éste último ha triunfado en el campo de las matemáticas por su facilidad para representar fórmulas. Sin embargo el usuario necesita completarlo con otro fichero para que el resultado adopte una forma de presentación adecuada en pantalla o al imprimir. Ese formato habitualmente es postscript. Con latex tampoco es posible editar diagramas y figuras complejas, por lo que se recurre a EPS (encapsulated postscript).

Postscript describe la apariencia visual de la página final y no permite al usuario cambiarla — una ventaja para el editor-, pero sus ficheros son demasiado extensos, por lo que no es un formato que haya superado el éxito de otros de menor tamaño como html o pdf.

Se trata de un "lenguaje de descripción de página" introducido en 1985 por Adobe Systems Incorporated. http://www.adobe.com

La descripción de las imágenes es independiente de las especificaciones de los dispositivos, por ejemplo la resolución de la impresora, por lo que puede ser
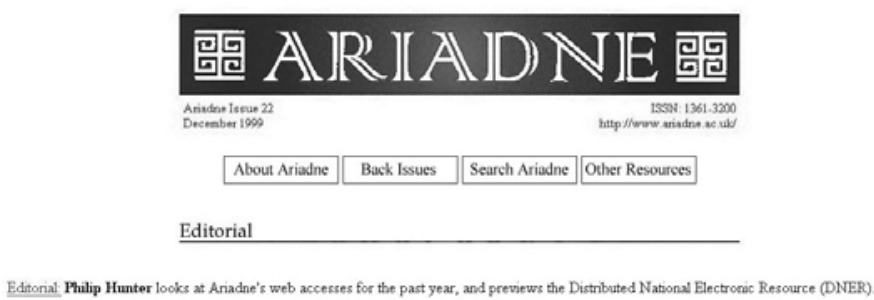

Main Articles

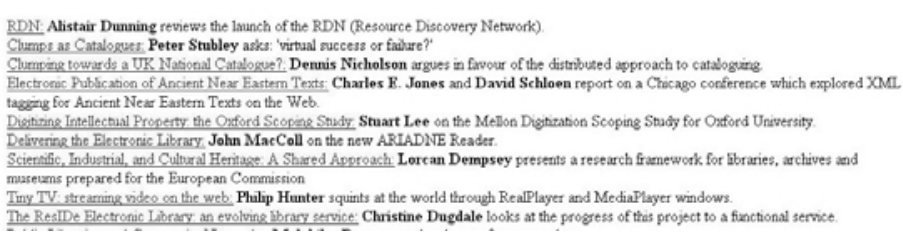

Revista-e Ariadne, n. 22, diciembre de 1999 http://www.ariadne.ac.uk 


\section{Un sondeo por las bibliotecas españolas}

Con el fin de acercarnos a la realidad de nuestras bibliotecas y centros de documentación se envió a finales de enero una encuesta a la lista de discusión IweTel. 15 centros especializados respondieron las preguntas y podemos afirmar que la casuística es tan variada como los tipos de bibliotecas que tenemos, si bien podrían agruparse en tres bloques: aquellas que tan sólo tienen acceso a unas cuantas revistas-e (por el momento se encuentran en una fase de prueba), las que acceden en torno a 200 publicaciones y las que superan el millar, éstas últimas a través de empresas distribuidoras de bases de datos.

A pesar de que en la actualidad la mayoría de las veces se trata de ediciones de las suscritas en papel, comienza a notarse un incremento de suscripciones exclusivamente a las versiones electrónicas, para lo que alegan el ahorro de espacio y de duplicados en centros de una misma red y la aparición de revistas que tan sólo se encuentran en formato electrónico. Sin embargo, por el momento no parecen dispuestos a abandonar del todo la versión impresa, sino más bien a complementarla.

Los motivos que llevan a la suscripción de revistas o versiones electrónicas son las ventajas que éstas ofrecen. Recogemos las que más relevancia tienen según la encuesta:

La rápida actualización de los contenidos, mucho antes de que llegue la versión papel.

La facilidad de acceso desde cualquier parte, sin acudir a la biblioteca — no siempre posible si se lleva a cabo por el número IP- y a cualquier hora.

La alta demanda por parte de los usuarios de este tipo de servicio.

Las opciones de búsqueda que permite un formato electrónico, como por ejemplo el hipertexto.

El coste, bajo o gratuito al disponer también de la versión en papel, hace que muchos centros prueben el nuevo formato con la intención de evaluar sus prestaciones.

La posibilidad de eliminar duplicados de revistas en las bibliotecas de una misma red, dejando sólo una en un centro y permitiendo su utilización desde los demás.

El acceso simultáneo de varios usuarios.

Las bibliotecas también consideran algunos inconvenientes que les hacen ser aún reacias a una implantación masiva de formatos electrónicos en sustitución del papel. Unos se derivan de la propia herramienta:

Requiere disponer de un número de ordenadores suficiente.

La lentitud del acceso a través de internet.

Es necesario imprimir los artículos para una lectura más cómoda.

Existe reticencia por parte de los usuarios no conocedores de herramientas informáticas.

Dificultad para el seguimiento del uso del servicio.

Otros problemas surgen de la falta de madurez de este formato para revistas:

No hay una garantía de acceso a los números atrasados.

La gestión de las suscripciones no está aun normalizada.

La forma de acceso mediante el uso de nombres de usuario y contraseñas resulta incómoda, y mediante números IP restringe el uso a ciertas máquinas, con lo que se anula una de las ventajas que de la distribución mediante internet.

Los sistemas de uso y formatos varían según los editores.

La tendencia observada en esta pequeña pero representativa muestra es que aumentan las suscripciones a revistas-e pero de momento con gran recelo para abandonar la versión en papel, aunque se afirma que va a depender de la política editorial que se imponga, ya que si se publica sólo de forma electrónica la única opción posible será suscribirse a ese formato.

Chu (1999) ha dado a conocer los resultados de una encuesta del mismo tipo realizada en EUA; las contestaciones de 50 centros dejan ver una gran coincidencia con las expuestas: como puntos positivos de las revistas-e se valoran especialmente la posibilidad de acceso remoto, el uso simultáneo de varios usuarios, la actualización de la información, los enlaces entre documentos y las capacidades de búsqueda. Por otro lado, los aspectos que frenan su uso mayoritario son la gran inversión necesaria para comenzar a dar este servicio (ordenadores, accesos, etc.), la necesidad de formar al personal y a los usuarios finales, los problemas no resueltos sobre los derechos de autor y la dificultad para el "hojeo" de forma electrónica.

usada en cualquier impresora postscript sin sufrir modificaciones.

A la hora de incluir un fichero de este tipo en un documento, el programa con el que se trabaja necesita conocer tanto el tamaño de la imagen postscript como el lugar de la página donde se desea colocar. Esta in- formación la ofrecen los ficheros que siguen la document structuring convention (DSC); en pocas palabras, se trata de un formato especial de fichero para documentos postscript que debe incluir comentarios. Un fichero EPS es un fichero postscript que, entre otras, sigue la norma de estructura de documentos DSC. 
$\underline{\text { Article Index }} \mid \underline{\text { Author Index }}$

2000 (Volume 5)

\begin{tabular}{|l|l|l|}
\hline Issue 1 (January 2000) & Issue 2 (February 2000) & Issue 3 (March 2000) \\
\hline Issue 4 (Apri 2000) & Issue 5 (May 2000) & Issue 6 (June 2000) \\
\hline Issue 7 (July 2000) & Issue 8 (August 2000) & Issue 9 (September 2000) \\
\hline Issue 10 (October 2000) & Issue 11 (November 2000) & Issue 12 (December 2000) \\
\hline
\end{tabular}

1999 (Volume 4)

\begin{tabular}{|l|l|l|}
\hline Issue 1 (January 1999) & Issue 2 (Febraary 1999) & Issue 3 (March 1999) \\
\hline Issue 4 (April 1999) & Issue 5 (May 1999) & Issue 6 (June 1999) \\
\hline Issue 7 (July 1999) & Issue 8 (August 1999) & Issue 9 (September 1999) \\
\hline Issue 10 (October 1999) & Issue 11 (November 1999) & Issue 12 (December 1999) \\
\hline
\end{tabular}

Índice de los números publicados por First Monday en 1999 http://www.firstmonday.dk/issues/index.html

Pdf fue creado en 1992 también por Adobe y sus ventajas le hacen tener una amplia aceptación en las revistas-e: permite hiperenlaces, anotaciones, indización y búsqueda de los documentos, control de la apariencia por parte del editor. Es un formato comprimido $\mathrm{y}$, además, las fuentes pueden ser incluidas en los documentos evitando por tanto tener que cargarlas en la impresora.

\section{El multimedia, un valor añadido.}

Otros formatos que complementan a los más puramente textuales son los denominados multimedia, que agrupan a los de imagen - ya se ha mencionado tiff, aunque hay otros como gif, o el sistema de compresión de gráficos jpeg-, los de vídeo — mpeg, avi, qts-, sonido (rara vez en revistas-e) y de realidad virtual. De estos últimos cabe destacar la importancia del vrml (virtual reality modelling language) p. ej. en revistas de química para representar distintas perspectivas de las moléculas y simulaciones (Wusteman, 1997).

Dentro del programa eLib (Electronic libraries programme), fundado por el Joint information systems committee (Jisc), se ha llevado a cabo una investigación sobre el papel de las revistas-e multimedia en las disciplinas académicas. Un ejemplo de este tipo de publicación puede verse en Earth interaction (Holoviak, 1997) y otras muchas recogidas en el web Bed (sm): $a$ registry of embedded multimedia electronic journals.

\section{http://EarthInteractions.org}

http://www.public.iastate.edu/ CYBERSTACKS/MBed.htm

\section{Política editorial}

Dentro de lo que se denomina revista-e es posible distinguir distintos tipos en función de las características a las que se atienen, ya sin considerar aquellas que tan sólo ofrecen los índices y resúmenes de los artículos que se van a publicar o que se han editado en soporte papel.

«Si se pretende que los autores
envíen a ellas sus trabajos es
imprescindible que las revistas-
e aparezcan recogidas en bases
de datos bibliográficas y en ín-
dices de citas, ya que así su di-
fusión será mayor»

Según la concepción de la propia revista, unas son la réplica electrónica de las ya existentes en papel, que es el caso más extendido, y otras se encuentran exclusivamente en soporte electrónico, bien desde su nacimiento (cada vez más frecuente), bien procedentes de anteriores publicaciones impresas (tendencia muy común últimamente). Un tercer caso sería el de las publicaciones tradicionales que han encontrado en los nuevos soportes una forma de extensión, es decir, recurren al formato electrónico para ampliar los artículos con fórmulas, esquemas e imágenes cuya calidad y extensión no siempre es posible abarcar en el papel. Este sistema se está utilizando principalmente en revistas de ámbito científico —-física, matemáticas, biología, etc.—.

Concurren diferentes motivos por los que los editores prefieren entrar poco a poco en el nuevo soporte sin abandonar su anterior forma: es conveniente dejar un período de familiarización, tanto para el usuario como para los propios editores, con el fin de detectar carencias y fallos, decidir el sistema de licencias de acceso y la forma de cobro, entre otros aspectos.

Sea cual sea el tipo de una revista-e, es posible distinguirlas por el medio de distribución. Si se considera como uno de los requisitos de su definición la transmisión por redes telemáticas esta distinción no ha lugar, ya que todas se distribuyen a través de internet; pero como ya se ha dicho, también se tendrán en cuenta aquellas en soporte óptico, ya que tanto su elaboración como su consulta requieren un ordenador.

Por el momento, las que circulan por la Red plantean el problema de la lentitud en la transmisión por un lado, y el de la inseguridad en el acceso por otro. En el caso del cd-rom se da el ejemplo de recopilaciones periódicas que el editor proporciona con los números atrasados publicados en papel y/o en línea. La biblioteca, o la institución suscrita a una revista en cd-rom, puede optar por ponerla en su red interna de cds (usando un juke-box o lector multidisco) o bien decidirse por volcar la información al disco duro de un ordenador servidor, para lo cual también necesita la licencia 
del editor, resultando además más caro de implementar y de administrar.

Otra forma de clasificar las revistas-e es la que atiende a las condiciones de suscripción: unas ofrecen acceso gratuito y otras suponen un gasto. Se da todo tipo de combinaciones: revistas en papel con versión electrónica para acceder gratuitamente a ésta, otras que precisan la suscripción en papel y, de esta forma, también se puede utilizar la versión electrónica sin coste adicional, o el mismo caso pero con un desembolso algo superior al de la suscripción impresa. Así mismo, aquellas que sólo existen en entorno electrónico pueden ser gratuitas o precisar suscripción.

\section{¿Qué hace que las bibliotecas se suscriban cada vez más a revistas-e?}

Las ventajas más importantes que ofrece el nuevo medio han sido recogidas por diversos autores como Alòs-Moner (1998), Keefer (1997) y García Testal y Barrueco (1997) entre otros. Son las siguientes:

- Facilidad de interrogación: permiten buscar en texto completo, visualizar los sumarios y utilizar operadores de búsqueda.

- La información puede actualizarse con mayor celeridad, con lo que se agiliza el tiempo de entrega. Aumenta la rapidez en la transmisión de la información.

- Se ahorra espacio de almacenamiento en las bibliotecas.

- No se pierden números ni se ven mutilados.

- Se ahorra en recursos materiales: papel, encuadernación y distribución.

- Se necesita menos personal para gestionar el control y la distribución.

- Pueden estar en varias plataformas: internet, cdrom o dvd.

- Si se accede a ellas a través de internet se pueden consultar desde cualquier parte sin necesidad de acudir a la biblioteca.

- Se hace más fácil la interacción de los investigadores entre sí, entre éstos y los usuarios y entre editores y autores.

- El hipertexto resulta de gran utilidad para obtener documentos relacionados con el que se está leyendo, sean de la misma revista, de otra o incluso de páginas web que no pertenezcan a ellas. No todos los formatos permiten esta utilidad (en un apartado anterior se trataron algunos de ellos de especial interés para la publicación de revistas-e).
- Se pueden dar con mayor facilidad servicios personalizados para ofrecer periódicamente a los usuarios los artículos publicados de su tema de interés.

- Debido a su bajo coste de edición y distribución en comparación con el soporte papel, podrá existir un número mayor de publicaciones con temas muy especializados que antes no podían financiarse por no contar con un número de investigadores suficientemente amplio que las justificaran.

En el cuadro número 4 "Un sondeo por las bibliotecas españolas" se presenta el punto de vista de los bibliotecarios en España, muy similar al de los de otros países.

\section{Pero ¿por qué su implantación no es tan rápida como se podría esperar?}

El principal motivo de que este nuevo concepto de revista no se haya instaurado con mayor rapidez - llamémosle contundencia - reside en los propios autores/investigadores. Ellos son el principio y el fin del ciclo: escriben los resultados de un estudio, los envían a la revista desde donde quieren que se divulga la cual acepta el artículo y lo publica, se distribuye, las instituciones la compran y los lectores/investigadores leen el trabajo.

\section{«Se debe planificar un sistema de archivo que asegure la per- manencia de los trabajos publi- cados»}

Los autores eligen principalmente las de mayor prestigio: cuanto más grande sea éste, mayor número de bibliotecas y organismos la comprarán, ya que será una revista muy solicitada por los lectores. El autor busca con la publicación de sus trabajos tener un impacto y un reconocimiento de la comunidad científica que no obtendrá si los envía a una revista de poca di-

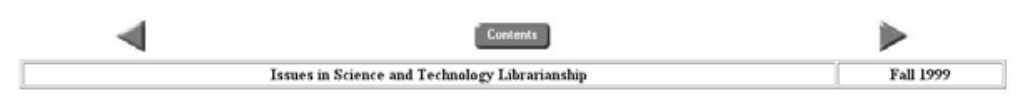

An Analysis of Science-Engineering Academic Library Positions in the Last Three Decades

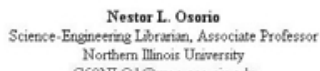

Northem Illinos Urewersity

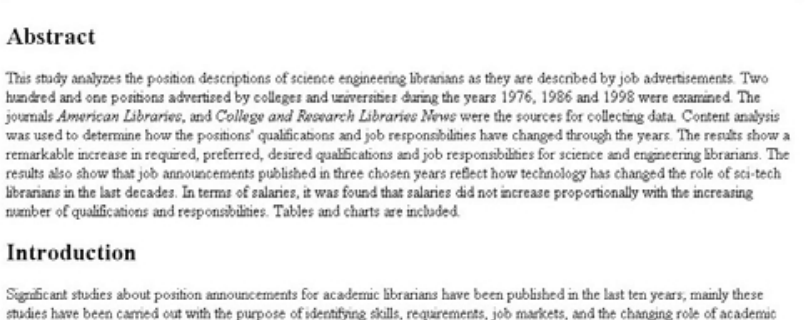

Artículo en Issues in science and technology librarianship http://www.library.ucsb.edu/istl 
fusión. Por el momento la mayoría de las revistas-e no gozan del renombre de las impresas, aunque esta situación va cambiando poco a poco y cada vez son más los investigadores que comienzan a utilizar este medio para dar a conocer sus textos, así como también aumenta el número de lectores que acuden a ellas para obtener información actualizada.

Sistematizando los requisitos necesarios para que las revistas-e puedan implantarse con éxito en la comunidad científica, y a los que han apuntado diversos autores (Barrueco y García Testal, 1997; García Testal y Barrueco, 1997; Keefer, 1997, etc.), diremos que los factores clave para que se dé este paso son los siguientes:

- Claridad en el sistema de venta. La mayoría de las editoriales no han decidido todavía la forma definitiva de llevar a cabo la producción, el marketing y el cobro. Respecto a éste actualmente se dan varios modelos: en unas ocasiones existe acceso gratuito, en otros lo es sólo para los suscriptores de la versión en papel. Se da el caso de que se pague un plus por sumarse a la nueva versión, o incluso que se deba abonar una cuota igual que la de la revista impresa con la intención de que a la larga los clientes la vayan abandonando a favor del texto electrónico. Las tarifas varían desde el cobro por suscripción de revista hasta el que tiene en cuenta el uso según el número de usuarios que pueden consultarla a la vez o dependiendo de la cantidad de artículos que se piden (Robnett, 1998). Por lo tanto, los mecanismos de acceso de los suscriptores a los artículos deben quedar claros, así como la forma de pago y el derecho de impresión de los trabajos.

- Regulación de la protección de los derechos de propiedad intelectual. En 1994 ya se planteó este asunto formalmente en la Conference on fair use (Confu), donde se pretendía dictar unas pautas de actuación. En la reunión de este grupo celebrada en mayo de 1998 todavía no se había llegado a un acuerdo (Linke, 1998).

- Aumento de prestigio científico. Este problema ya comentado anteriormente frena a los autores a elegirlas como medio de difusión de sus trabajos. El sistema electrónico peca de ser efímero: lo que hoy se encuentra en una dirección web mañana puede que ya no esté, y el papel, en cambio, cuenta con un peso de autoridad, de estabilidad. Deberán establecerse medios que aseguren también esa firmeza en el entorno virtual de manera que no sea posible modificar los artículos ya publicados, puesto que sólo la información estable puede ser criticada. Esto no excluye que puedan elaborarse nuevas versiones de trabajos ya publicados con el fin de integrar los avances y comentarios de otros investigadores, como se está haciendo en algunas publicaciones (Roberts, 1999). Si se pretende que los autores envíen a ellas sus investigaciones es imprescindible que las revistas-e aparezcan recogidas en bases de datos bibliográficas y en índices de citas, ya que así su divulgación será mayor.

- Aunque por el momento no sea lo más frecuente, la revista-e debe ser concebida como tal desde su inicio, evitando que se queden en versiones digitales de publicaciones en papel. La mayoría se encuentran en esta situación: revistas existentes que a modo de prueba deciden adoptar una nueva forma complementaria a la que tenían.

- Debe establecerse un sistema de control de calidad por medio de un consejo asesor; el procedimiento electrónico agiliza el envío de artículos y correcciones entre autores y editores. Además, los lectores podrán opinar acerca de los trabajos publicados con mayor facilidad, constituyendo incluso foros de discusión (Roberts, 1999).

- Es preciso que se imponga una normalización en cuanto a la forma de presentación, estructura y citas a recursos electrónicos accesibles desde el propio artículo.

- Se debe planificar un sistema de archivo que asegure la permanencia de los trabajos publicados. Éste es uno de los problemas que más inseguridad plantea a los posibles clientes de revistas-e (principalmente bibliotecas y centros de información en general). Alòs-Moner (1998) y Keefer (1998) enumeran algunas cuestiones como: qué ocurrirá si se cancela una suscripción, si la editorial decide dejar de publicar un título o si incluso cierra la empresa?, se seguirá teniendo acceso a los ficheros de números anteriores? Una solución llevada a cabo por algunas editoriales consiste en enviar periódicamente un cd-rom con esos números. Esta opción puede servir por el momento, aunque si cambia la tecnología (en hard o en soft), \&ómo se podrán leer esos archivos?

Si la legislación de derechos de propiedad intelectual que atañe a la revista permite volcar a un disco local la información de los números a los que está suscrita la biblioteca, se pueden adoptar soluciones como el servicio ECO (Electronic collection online) de Oclc, que funciona desde junio de $1997 \mathrm{y}$ hace de puente entre las editoriales y los centros adheridos al servicio. Éstos se suscriben a las revistas directamente con el editor, con una agencia de suscripciones o a través de Oclc, que se encarga de almacenarlas permanentemente, gestionar los archivos, ofrecer su sistema de recuperación de información y proveer el acceso a las bibliotecas suscriptoras.

http://www.oclc.org/oclc/menu/eco.htm 
Keefer (1997) propone algunos consejos para que las revistas-e puedan gozar del éxito que ostentan las publicaciones en papel. Nos basamos en esta autora para proponer los siguientes:

1. Posibilidad de imprimir los artículos. Para los lectores no es cómoda la lectura en pantalla y suelen recurrir a la impresión para hacer de los artículos documentos "portátiles", poder subrayarlos, anotar en sus márgenes, etc. Las bibliotecas se están alarmando en este aspecto, ya que han visto aumentado en gran medida el gasto de papel y comienzan a tomar medidas como el cobro por impresión.

«La falta de prestigio científico
frena a los autores a elegirlas
como medio de difusión de sus
trabajos. El medio electrónico
peca de ser efímero: lo que hoy
se encuentra en una dirección
web mañana puede que ya no
esté»

2. Interfaz fácil de entender y de usar. En primer lugar, una gran cantidad de usuarios consideran que no merece la pena aprender a usar un nuevo medio si no ofrece una gran cantidad de información. Por eso es importante que se diseñen interfaces amigables que animen a estas personas a usarlas. En segundo lugar, está comprobado que la lectura en un monitor es entre un $25 \%$ y un $30 \%$ más lenta que en papel y que un lector de texto electrónico pierde aproximadamente un $40 \%$ de la información que aparece en pantalla. Esto tendrá que ser tenido en cuenta por el editor para diseñar interfaces cómodas de leer.

3. Una vez que un lector ha visitado una revista-e es importante conseguir que vuelva a hacerlo en otra ocasión. Esto tiene sentido especialmente en las de distribución gratuita, donde el éxito no va a radicar en el número de suscripciones, sino de visitas recibidas.

4. Las revistas-e deben asemejarse en lo posible a las tradicionales en cuanto a la posibilidad de "hojear". Es lo que da lugar a la llamada serendipity: encontrar información de interés "paseando" por delante de las estanterías y abriendo algunas revistas. Actualmente se está desarrollando software que simule esta función que tanta importancia tiene para incentivar la creatividad. También ha de imitarse la movilidad dentro de la publicación, lo que se facilita con las opciones del hipertexto. El usuario debe poder avanzar en la lectura, retroceder y volver al sumario con facilidad.

\section{Sistemas de acceso a revistas-e: proyectos editoriales y servicios intermediarios}

Entre los proyectos pioneros destacan por su importancia Eies (1976-1981), Blend (1980-1985), Core (1991-1995), Stelar (1991-1995), Tulip (1991-1996), Elvyn (1992-1995) y RedSage (1992-1996), además de Adonis para cd-rom comenzado en 1980, y hoy un producto comercial. Se trataba de colaboraciones entre editoriales y bibliotecas universitarias. No pudieron alcanzar demasiado éxito por no existir en ese momento la tecnología apropiada pero sí consiguieron su objetivo: estudiar la implantación de revistas-e en el ámbito académico, conocer los problemas que surgían y plantear soluciones.

\section{Editores.}

Los primeros que lanzaron revistas-e fueron, entre otros:

- Academic Press. Su servicio International digital electronic access library, conocido como Ideal, ofrece casi 200 revistas a texto completo en formato pdf en la web, y el ritmo de crecimiento es de 2.000 artículos al mes. En este proyecto colaboran diversas instituciones como Fujitsu, Bath University y otros editores. A pesar de ser un servicio de pago es posible acceder de forma gratuita a los índices y a los resúmenes.

http://www.idealibrary.com

- Blackwell Science. Este editor publica más de 200 revistas de sociedades científicas; el texto se encuentra en pdf y las cabeceras en sgml. En lugar de disponer de un servidor propio, ofrece el acceso a través de otros organismos. Hay que resaltar que un $90 \%$ de sus publicaciones son exclusivamente en línea. A través del servicio Synergy (conocido antes como SteamLine) ofrece revistas a texto completo.

http://www.blacksci.co.uk

http://www.blackwell-science.com

- Elsevier Science. Su servicio Elsevier electronic subscription (EES), en marcha desde 1995, ofrece acceso a más de 1.200 revistas editadas a través de la Red (unas son versiones de las impresas y otras son sólo revistas-e). Además de recibir los artículos en línea, los suscriptores disponen de diversos servicios de DSI, de un foro de discusión y permite obtener licencias para descargar las revistas en un servidor local. Science direct da acceso a más de 1.100 publicaciones de $E l$ sevier y hace posible a otros editores que pongan sus páginas en su servidor. Este servicio hace necesario que sus usuarios dispongan del software Orion scientific's science server (Marcos, 1998a). 
http://www.elsevier.nl

http://www.elsevier.com

- HighWire Press. En este caso se ha producido una colaboración entre las bibliotecas de la Universidad de Stanford y Academic Information Resources para ofrecer los trabajos a texto completo en la web de ciertas revistas de ámbito científico, la mayoría de medicina.

\section{http://highwire.stanford.edu}

- John Wiley \& Sons. Más lentamente que las anteriores, esta editorial también está llevando a cabo la edición de sus publicaciones periódicas en versión electrónica.

http://www.wiley.com

- Muse. Se trata de una colaboración entre John Hopkins University Press y la biblioteca Milton Eisenhower, ofreciendo acceso electrónico y archivo local de los textos de muchas de las revistas publicadas por dicha universidad.

http://muse.jhu.edu

- Springer Verlag. Ya en el año 1993 esta empresa anunciaba un servicio para enviar por correo electrónico a sus usuarios los índices de 30 de sus revistas antes de que se publicaran en papel. Un año después colaboraba en el proyecto RedSage para ofrecer imágenes de más de 1.000 publicaciones periódicas. Más recientemente, en 1997, lanzó Link, que ya cuenta con la mayoría de sus revistas, algunos libros y publicaciones también de otras empresas. Además de mostrar los sumarios, dispone de un motor que busca a texto completo en los artículos (OpenText), un foro de discusión y un servicio de alerta (Marcos, 1998b).

http://www.springer.de

«Es conveniente dejar un período de familiarización tanto para el usuario como para los propios editores con el fin de detectar carencias y fallos, decidir el sistema de licencias de acceso y la forma de cobro, entre otros aspectos»

- Swets \& Zeitlinger Publishers. La compañía Swets \& Zeitlinger es más conocida por su condición de agente de suscripciones y ahora también como distribuidora (ver el siguiente apartado), pero su división SZP edita 38 de sus revistas en pdf (entre ellas El profesional de la información).

http://www.swets.nl/sps/journals/jhome.html
- Taylor \& Francis. En colaboración con Psychology Press Journals ofrece unas 30 revistas a través de la Red al mismo precio que tienen en papel y algo más caro si se eligen ambos soportes. Se sirve del software de edición electrónica RealPage usado por CatchWord quien, a su vez, asume el papel de "archivo electrónico". El cliente RealPage es gratuito y posee las características de permitir buscar a texto completo, contar con recursos multimedia y ofrecer formatos de salida no sgml como postscript.

\section{Distribuidores.}

Las grandes casas de distribución de bases de datos de información científica cuentan con sus servicios específicos para ofrecer acceso a paquetes de revistas-e:

- Ovid. En 1997 (IWE, v. 6, n. 1-2, p. 3) sus bases de datos se anunciaron como las primeras recopilaciones electrónicas de revistas de medicina disponibles comercialmente y dotadas de enlaces hipertexto a citas bibliográficas de Medline. Además, desde ese año ofrece un servicio de acceso a la información mediante un servidor remoto en internet con una cuota fija anual. El sistema Ovid full text proporciona el texto completo de los artículos de revistas de distintos editores en formato sgml. Cuando se trata de localizar recursos propios de Ovid se puede utilizar el servicio Journal@Ovid, que da acceso a más de 300 revistas-e en línea o a 100 en cd-rom. La novedad viene de la mano del servicio OpenLinks, que permite enlazar con otros sitios externos a Ovid y que ha sido anunciado en diciembre de 1999.

http://www.ovid.com

- SilverPlatter. El sistema SilverLinker permite llegar al artículo en texto completo electrónico desde el registro bibliográfico. Entre los servidores a los que enlaza destacan Ideal de Academic Press, Link de Springer-Verlag, SwetsNet de Swets, Muse, InformationQuest de Dawson, Ebsco Online, etc.

http://www.silverplatter.com

- Ebsco. Ebsco Publishing y EbscoHost están ocupando puestos destacados en el mercado con sus paquetes de información que autorizan a los usuarios a acceder a miles de publicaciones periódicas en texto completo, así como a los índices y resúmenes, con unos precios sensiblemente más bajos que los obtenidos cuando se realizan suscripciones aisladamente. Ebsco Publishing incorpora más de 2.000 revistas a texto completo a sus bases de datos y además combina el acceso remoto a EbscoHost con la instalación en la red local de los cd-roms equivalentes (Marcos, 1998c).

http://www.ebsco.com 
- Oclc. La idea de FirstSearch electronic collections online (Eco) ha servido de base para el desarrollo de otros proyectos de tipo comercial (véase la descripción hecha de este servicio anteriormente en el último punto del apartado "Pero por qué su implantación no es tan rápida como se podría esperar?”).

http://www.oclc.org

- Swets \& Zeitlinger (desde su reciente compra de Blackwell, la división de suscripciones y de acceso a revistas electrónicas se llama Swets Blackwell). El producto SwetsNet ofrece varias posibilidades en cuanto a la suscripción, el acceso y el archivo de números atrasados de las revistas-e. El catálogo de recursos disponibles (información sobre 15.450 revistas de 4.550 editores) se presenta en formato $\mathrm{html}$, mientras que los textos completos (más de 3.100 revistas) se encuentran en pdf. Una ventaja es que se puede integrar en el catálogo de la biblioteca.

http://www.swetsnet.com

- Information Quest. Este nombre pertenece tanto a una compañía de Dawson como al producto al que nos referimos. Proporciona una interfaz de consulta a revistas-e en línea a través de la web. La herramienta $I Q$ search permite leer el resumen de los artículos y decidir si se quiere recibir por fax o en pantalla. El usuario puede suscribirse a revistas completas o elegir el sistema de pay-per-view.

http://www.informationquest.com

- Bell \& Howell Information and Learning (antes $U M I$ ), a través de su servicio ProQuest direct, facilita los sumarios de más de 6.000 publicaciones y el texto completo de más de 3.000 en formato imagen o texto más gráficos (Marcos, 1998d; Epi, 1999, v. 8, n. 7-8).

http://www.umi.com

- The Dialog Corporation. Su nuevo servicio de enlace a texto completo desde los registros bibliográficos o los resúmenes de OnDisc se conoce como Gold eDocs.

http://www.dialog.com/edocs

\section{Gestión en bibliotecas}

Alòs-Moner (1998) observa que con el aumento de revistas-e —casi siempre versiones de las ediciones en papel- los usuarios se encuentran ante la duda de qué formato elegir y, en el caso de decidirse por el digital, si suscribirse a varias o contratar un servicio de acceso que las incluya. A estas cuestiones se añade la decisión de si suscribirse a revistas completas o solicitar a su distribuidor sólo los artículos que necesiten. La novedad de este producto hace que todavía no existan respuestas a muchas de las preguntas que los bibliote- carios se hacen, por eso conviene considerar los aspectos que ya tenía en cuenta a la hora de suscribir publicaciones en papel (por ejemplo, el uso potencial que harán de la revista los usuarios por la temática y la calidad) y algunos otros que afectan a las publicaciones electrónicas:

- Los medios informáticos que se poseen en el centro: el hardware, el software, la red local, el acceso a internet, la cantidad de equipos al servicio del personal y de los usuarios, en qué formato se distribuye la revista y por qué medio.

«Debido a su bajo coste de edi-
ción y distribución, en compara-
ción con el soporte papel, podrá
existir un número mayor de pu-
blicaciones con temas muy es-
pecializados que antes no podí-
an financiarse por no contar
con un número de investigado-
res suficientemente amplio que
las justificaran»

- El valor añadido que supone contar con la versión electrónica: si dispone de un motor de búsqueda, hipertexto, si integra imágenes u otros documentos multimedia, si su contenido es el mismo que el de la versión en papel o si en cambio le faltan algunas partes (a veces sólo se publican en la Red algunos artículos y no otros, o se eliminan apartados como reseñas, cartas al director, etc.).

- La manera en que se registrarán los números que vayan "llegando", teniendo en cuenta que en algunas publicaciones cambia el concepto de número, ya que se van publicando artículos de forma independiente sin adscribirlos a ningún volumen, número o fascículo.

- La forma en que se quiere dar acceso a los usuarios, esto es, si deben acudir a la institución para conectarse desde ordenadores con un número IP permitido o si van a poder trabajar desde cualquier otro lugar con un sistema de contraseña.

- El método de catalogación de estos recursos; por el momento no son muchas las bibliotecas que realizan esta operación, pero parece que el modo más aceptado es la inclusión del campo 856 en formato Marc dentro del registro correspondiente a la publicación en papel. De este modo se puede proporcionar acceso a las revistas desde el propio opac.

- La política de impresión que se va a seguir: gratuita o de pago, como ha ocurrido con las fotocopias.

- El coste de la formación, primero del personal y después de los usuarios. 
- El archivo de los números anteriores es un asunto importante que debe valorarse antes de abandonar la versión en papel. En algunos casos las editoriales se están haciendo cargo, pero es posible que haya cambios.

- La imposibilidad en muchas ocasiones de ofrecer el servicio de préstamo interbibliotecario debido a restricciones contractuales impuestas por algunas editoriales.

- Los procedimientos para medir el uso que se hace de las revistas es una información de gran importancia para modificar la política de suscripciones: qué revistas conviene o no mantener y, de las que se compren, cuáles dejar en ambos formatos y cuáles no.

\section{Algunas referencias de interés}

Alòs-Moner, A. d'. "Preguntas y respuestas sobre revistas electrónicas". En: El profesional de la información, 1998, abril, v. 7, n. 4, pp. 14-16.

Barrueco, J. M.; García Testal, C. "Panorama actual y posibilidades futuras en revistas electrónicas". En: Information world en español, 1997, marzo, v. 6, n. 3, pp. 19-22.

Brown, E.; Duda, A. "Electronic publishing programs: issues to consider". En: Issues in science and technology librarianship, 1996. Consultado en 15-01-00.

http://www.library.ucsb.edu/istl/96-fall/brown-duda2.html

Brown, E.; Duda, A. "Electronic publishing programs in science and technology. Part 1: the journals". En: Issues in science and technology librarianship, 1996-1997. Consultado en: 15-01-00.

http://www.library.ucsb.edu/istl/96-fall/brown-duda.html

Chartron, G. "La presse périodique scientifique sur les réseaux". En: Solaris, 1996, n. 3.

http://www.info.unicaen.fr/bnum/jelec/Solaris/d03/3chartron.html

Chartron, G. Revues scientifiques et internet. 1996 (actualizado en 1999). Consultado en: 15-01-00.

http://www.urfist.jussieu.fr/urfist/revues.htm

Chu, H. "Electronic journals: promises and challenges for academic libraries". En: Chinese librarianship: an international electronic journal, 1999, diciembre, n. 8. Consultado en: 15-01-00.

http://library.fgcu.edu/iclc/cliej/cl8chu.htm

http://phoenix.liu.edu/ hchu/ejournal.htm

Eason, K., [et al.]. A comparative analysis of the role of multi-media electronic journals in scholarly disciplines. 1997. Consultado en: 15-01-00. http://www.ukoln.ac.uk/services/elib/papers/tavistock/eason/eason.html

Edwards, J. "Electronic journals: problem or panacea?". En: Ariadne, 1997, n. 10.

http://www.ariadne.ac.uk/issue10/journals

García Testal, C.; Barrueco, J. M. "El panorama editorial en la revolución electrónica”. En: Information world en español, 1997, junio, v. 6, n. 6, pp. 12-14.

Holoviak, J.; Seitter, K. "Transcending the limitations of the printed page". En: Journal of electronic publishing, 1997, septiembre, v. 3, n. 1. Consultado en: 15-01-00.

http://www.press.umich.edu/jep/03-01/EI.html

Keefer, A. "Proyecto Tulip: análisis crítico". En: Information world en español, 1996, n. 42, pp. 24-25.

Keefer, A. "La revista electrónica y su aceptación por parte del usuario final”. En: Anuario Socadi de documentación e información. Barcelona: Socadi, 1997, pp. 185-190.

Keefer, A. "Los archivos de revistas electrónicas y ECO”. En: El profesional de la información, 1998, julio-agosto, v. 7, n. 7-8, pp. 39-42.
Kidd, T. “Are print journals dinosaurs?”. En: Ariadne, 1997, n. 12. Consultado en: 15-01-00

http://www.ariadne.ac.uk/issue12/main

Knudson, F., [et al.]. "Creating electronic journal web pages from opac records". En: Issues in science and technology librarianship, 1997. Consultado en: 15-01-00.

http://www.library.ucsb.edu/istl/97-summer/article2.html

"La biblioteca virtual ProQuest SiteBuilder". En: El profesional de la información, 1999, julio-agosto, v. 8, n. 7-8, pp. 37-38.

Le Crosnier, H. "Les journeaux scientifiques électroniques ou la communication de la science àheure du réseau mondial”. En: Solaris, 1996, n. 3. Consultado en: 15-01-00.

http://www.info.unicaen.fr/bnum/jelec/Solaris/d03/3lecrosnier.html

Linke, E. "On beyond copyright”. En: The serials librarian, 1998, v. 33, n. 1-2, pp. 71-81.

Luijendijk, W. "Archiving electronic journals: the serials information providers̉ perspective”. En: Ifla journal, 1996, v. 22, n. 3, pp. 209-210.

Marcos Mora, M. C. (a). "Elsevier science: editorial y servicio de información”. En: El profesional de la información, 1998, octubre, v. 7, n. 10, pp. 33-35.

Marcos Mora, M. C. (b). "Springer-Verlag, del papel a la pantalla". En: El profesional de la información, 1998, diciembre, v. 7, n. 12, pp. 32-33.

Marcos Mora, M. C. (c). "Ebsco information services". En: El profesional de la información, 1998, mayo, v. 7, n. 5, pp. 17-20.

Marcos Mora, M. C. (d). "La respuesta de UMI". En: El profesional de la información, 1998, junio, v. 7, n. 6, pp. 27-29.

Moreno de la Fuente, A. "Revistas electrónicas en internet". En: Information world en español, 1997, mayo, v. 6, n. 5, pp. 13-17.

Nisonger, T. "Collection management issues for electronic journals". En: Ifla journal, 1996, v. 22, n. 3, pp. 233-239.

"Ovid: la auténtica biblioteca virtual". En: Information world en español, 1997, enero-febrero, v. 6, n. 1-2, pp. 1-4.

Peek, R.; Pomerantz, J. "Electronic scholarly journal publishing”. En: Annual review of information science and technology, 1998, v. 33, pp. 321356.

Redero, L. A. "Buscadores de revistas electrónicas". En: El profesional de la información, 1998, abril, v. 7, n. 4, pp. 3-6.

Roberts, P. "Scholarly publishing, peer review and the internet". En: First monday, 1999. Consultado en: 15-01-00. http://www.firstmonday.dk/issues/issue4 4/proberts

Robnet, B. “Online journal pricing”. En: The serials librarian, 1998, v. 33, n. 1-2, pp. 55-69.

Rowland, F. "Electronic journals: delivery, use and access". En: Ifla journal, 1996, v. 22, n. 3, pp. 226-228.

Stackpole, L.; King, R. J. "Electronic journals as a component of the digital library". En: Issues in science and technology librarianship, 1999. Consultado en: 15-01-00.

http://www.library.ucsb.edu/istl/99-spring/article1.html

Valauskas, E. "Electronic journals and their roles on the internet". En: The serials librarian, 1998 , v. 33, n. 1-2, pp. 45-54.

Villalón, J.; Aguillo, I. "Revistas electrónicas en ciencias sociales y humanidades". En: Revista española de documentación científica, 1998, v. 21, n. 3, pp. 303-316.

Wusteman, J. "Formats for the electronic library." En: Ariadne, 1997, n. 8. Consultado en: 15-01-00.

http://ukoln.bath.ac.uk/ariadne/issue8/electronic-formats

\section{Mari-Carmen Marcos}

mcmarcos@posta.unizar.es 